\title{
Retracted: Structural and Optical Properties of Germanium Thin Films Prepared by the Vacuum Evaporation Technique
}

\section{Physics Research International}

Received 10 September 2014; Accepted 10 September 2014; Published 16 September 2014

Copyright (C) 2014 Physics Research International. This is an open access article distributed under the Creative Commons Attribution License, which permits unrestricted use, distribution, and reproduction in any medium, provided the original work is properly cited.

The paper titled "Structural and Optical Properties of Germanium Thin Films Prepared by the Vacuum Evaporation Technique" [1], published in Physics Research International, has been retracted as it is essentially identical in content; the paper contains identical figures from a previously published paper titled "Nanocrystalline formation and optical properties of germanium thin films prepared by physical vapor deposition," by A. A. Akl and H. Howar, which was published in Journal of Physics and Chemistry of Solids, Volume 70, Issue 10, October 2009, Pages 1337-1343.

\section{References}

[1] Z. Al-Sharafi, S. Mohyeddine, S. Osman Mohammed, and R. M. Kershi, "Structural and optical properties of germanium thin films prepared by the vacuum evaporation technique," Physics Research International, vol. 2014, Article ID 594968, 7 pages, 2014. 


\author{
Z. Al-Sharafi, ${ }^{1}$ S. Mohyeddine, ${ }^{1}$ Samir Osman Mohammed, ${ }^{2}$ and R. M. Kershi ${ }^{2}$ \\ ${ }^{1}$ Physics Department, Applied Science Faculty, Taiz University, Taiz, Yemen \\ ${ }^{2}$ Physics Department, Science Faculty, Ibb University, Ibb, Yemen
}

Correspondence should be addressed to R. M. Kershi; rkershil@gmail.com

Received 31 October 2013; Accepted 27 December 2013; Published 17 February 2014

Academic Editor: Ravindra R. Pandey

Copyright (C $2014 \mathrm{Z}$. Al-Sharafi et al. This is an open access article distributed under the Creative Commons Attribution License, which permits unrestricted use, distribution, and reproduction in any medium, provided the original work is properly cited.

Germanium (Ge) thin films have been deposited onto the glass substrates by the vacuum evaporation technique. The effect of annealing temperature on the structural and optical properties of the germanium thin films was investigated. The structural and optical properties of thin films were characterized by XRD, SEM, and UV-Vis techniques. XRD results showed that the structure of the deposited thin films changed from amorphous phase for the films, which deposited at room temperature, to crystalline phase for the films, which deposited at high temperature. Optimum temperature to obtain a good crystalline structure was $525^{\circ} \mathrm{C}$. The SEM image also showed that the crystallization of the thin films is increased with increasing of annealing temperature. Transmittance and reflectance spectral were used to calculate the absorption coefficient. Two absorption edges in two spectral regions were distinguished according to direct and indirect electron transitions. Energy band gap $E_{g}$ was calculated by using the Tauc relationship for both direct and indirect electron transitions. The average value of $E_{g}$ was equal to $0.79 \mathrm{eV}$ and $0.61 \mathrm{eV}$ for direct and indirect transitions, respectively.

\section{Introduction}

Germanium is an indirect semiconductor and it has a face centered cubic crystal lattice structure of diamond type with a lattice constant of $a=5.657 \AA$. Germanium is a typical semiconductor carrying a specific resistance of $500 \mathrm{~cm}$ at room temperature. Germanium-based materials are in use for light emitting devices [1], infrared sensors [2], and solar cells [3]. Due to the possibility of obtaining different values for the conductivity, germanium has a broad area of usage of the semiconductors such as current resistors, photovoltaic cells, and other electronic devices and appliances. The related indirect electron transitions are with higher probability responsible for absorption and emission of light. For this case, the width of the energy gap is given by $0.6 \leq E_{\mathrm{gi}} \leq$ $0.8 \mathrm{eV}$. It can be observed another bottom of the conduction band, which is directly above the maximum of the valence band, and the related direct energy gap is given by $E_{\mathrm{gd}} \geq$ $0.8 \mathrm{eV}$ [4-7]. The width of the band gap becomes smaller with increasing temperature. Due to the thermal expansion, the lattice constant changes which causes a change in the band structure which is small [6]. For example at a variation of the temperature to $291^{\circ} \mathrm{K} E_{g}$ varies by $(0.6 \mathrm{eV}-0.75 \mathrm{eV})[6,7]$.

Therefore, in germanium, light absorption can occur in the beginning at energy of $0.6 \mathrm{eV}$ due to indirect transitions and at $0.8 \mathrm{eV}$ due to direct transitions. The value of the extinction coefficient for germanium is given by around $10^{2} \mathrm{~cm}^{-1}$ in the first region, $10^{-4} \mathrm{~cm}^{-1}$ in the second region, and increases up to $10^{6} \mathrm{~cm}^{-1}$ if the photon energy becomes larger than $3.0 \mathrm{eV}$ [6]. Germanium films deposited at the room temperature are in the amorphous phase. In principle germanium begins to crystallize at higher temperatures [8], which occur above a substrate temperature of $T_{s}>$ $300^{\circ} \mathrm{C}$. When the substrate temperature reaches $800^{\circ} \mathrm{C}$, the germanium film is expected to be single crystalline with a reflection corresponding to the one of single crystalline bulk germanium. On the other hand, the reflection coefficient of germanium films exceeds the value corresponding to bulk germanium [9]. It is possible to transform amorphous deposited films into crystalline structure by annealing the 
specimens in vacuum at $300^{\circ} \mathrm{C}$ [10]. This multiplicity of properties makes such films suitable for broad usage in manufacturing a number of electronic devices such as light detectors, heterojunctions, and sensors for temperature and magnetic field. In the research for cheap substrates for electronic devices, thin films of germanium deposited on glass appear to be an excellent candidate, if one succeeds in obtaining a grain-like structure [11]. Succeeded in growing amorphous films of $2000 \AA$ on glass and in improving the structure and obtaining crystals by annealing at temperatures around 500 and $600^{\circ} \mathrm{C}$. Similarly it was possible to crystallize layers of amorphous germanium deposited on a film of gold, where the crystallization depended on the continuity of the gold layer and on the thickness of the amorphous germanium layer [12]. The goal of this paper is to study the effect of annealing temperature on structural phase of germanium thin films and there optical properties.

\section{Experimental Details}

Germanium thin films of purity $99.99 \%$ were deposited on clean glass plates $(2 \mathrm{~cm} \times 4 \mathrm{~cm})$ using an evaporation device (furnace) of model Edwards Auto 306 thermal evaporation in vacuum at pressure $10^{-6} \mathrm{mbar}$. The distance between the germanium evaporation source (boutique min Tungsten $\mathrm{W}$ ) and the rotating disk was $14.0 \mathrm{~cm}$. The velocity of the deposition was greater than $0.3 \mathrm{~nm} / \mathrm{s}$ for all samples. For the transition from the amorphous to the crystalline phase, the initially amorphous films were annealed using a furnace of type CARBOLITE CWF-1200 that allows fixing the temperature electronically to the annealing temperature desired in the experiment. The annealing procedure was performed in separate steps, where each step had a definite temperature and annealing duration. The temperature ranged from initially $100^{\circ} \mathrm{C}$ up to $575^{\circ} \mathrm{C}$, and the time interval from 10 min until $60 \mathrm{~min}$. The X-ray spectrum was carried out using X-Ray diffractometer (model PW generator 1830) to investigate the structure of the deposited films. The scanning range of $2 \theta$ was restricted to the range $20-80^{\circ}$. The thickness of the thin films was measured using a VEECO DEKTAK3 profilometer. The surface morphology of the films was analyzed using a scanning electron microscope (SEM). Using a spectrophotometer of type JASCO-570, we scanned the transmittance $(T)$ and reflectance $(R)$ spectra in the spectral region of $\lambda>400 \mathrm{~nm}$ to obtain an optical characterization of the films.

\section{Results and Discussion}

$\mathrm{X}$-Ray diffraction of germanium thin films is shown in Figure 1 as a typical spectrum for the films, which were deposited on glass substrates at room temperature. The spectra showed that all samples have an amorphous structure. Figure 2 shows the XRD spectra of the germanium thin films that were annelid to up to $450^{\circ} \mathrm{C}$ for duration of $30 \mathrm{~min}$ have amorphous phase, since there are no peaks pointing out the crystalline structure, whereas shows clearly the onset of crystallization after annealing to a temperature of $500^{\circ} \mathrm{C}$.

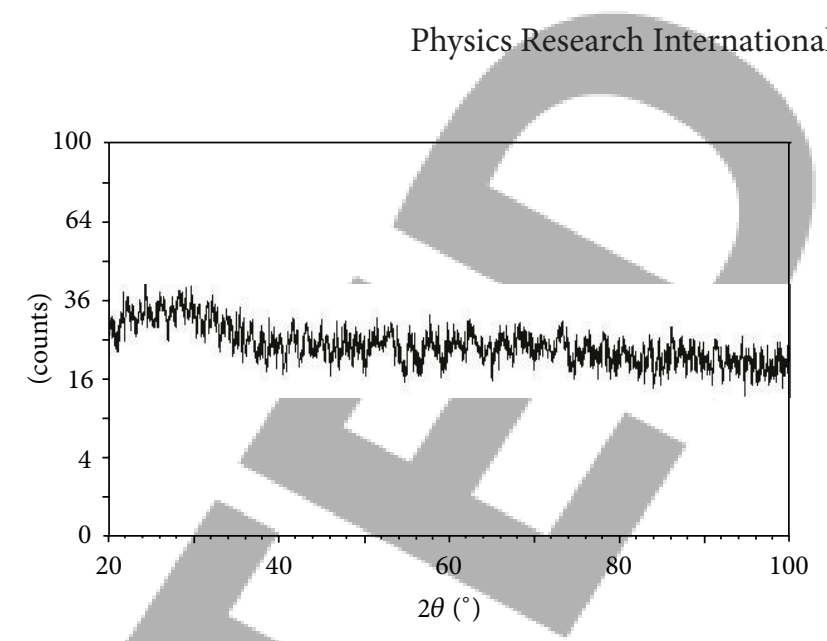

FIGURE 1: Example for the XRD spectrum of germanium films deposited at room temperature.

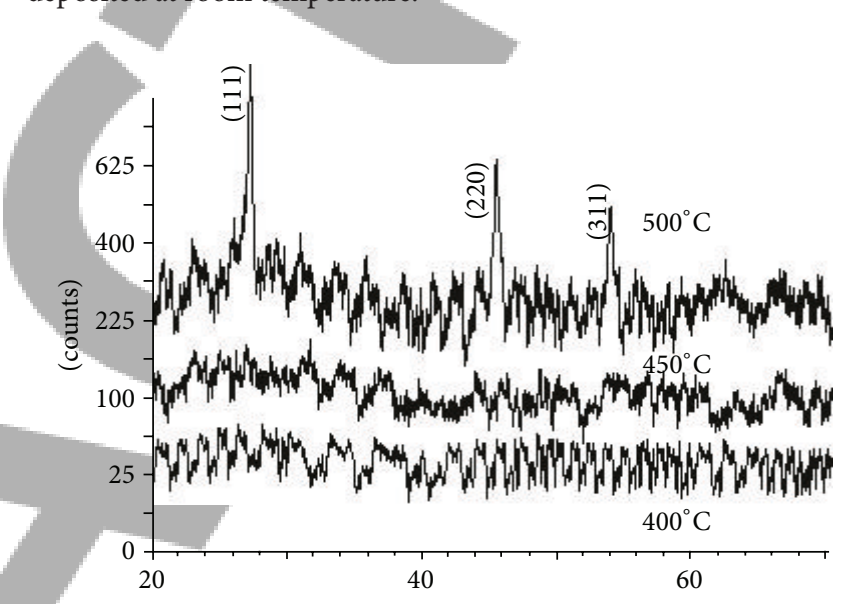

FIGURE 2: Example of the XRD spectra for films as a function for annealing temperatures: $400^{\circ} \mathrm{C}, 450^{\circ} \mathrm{C}$, and $500^{\circ} \mathrm{C}$.

Figures 3(a), 3(b), and 3(c) show an example for a comparison of XRD spectra of germanium films that annelid to various temperatures $\left(500^{\circ} \mathrm{C}, 525^{\circ} \mathrm{C}\right.$, and $\left.550^{\circ} \mathrm{C}\right)$. In this way, it was shown that the temperature adequate for the transformation from the amorphous to the crystalline phase was $525^{\circ} \mathrm{C}$, for films of moderate thickness $(500-1000 \mathrm{~nm})$. Here it is noticed that the relative strength of the peaks is highest at $525^{\circ} \mathrm{C}$, while the strength decreases at $550^{\circ} \mathrm{C}$, and the peaks disappear completely at $600^{\circ} \mathrm{C}$. The origin of this might be that the annealing procedure as explained in Figure 2 is suitable up to $550^{\circ} \mathrm{C}$ and above that the germanium film transforms itself into a soft substance, a part of which sticks to the surface of the glass which is placed above the film, and as a consequence there is not enough material in the remainder such that granules can build up in the film. The average values of the lattice parameters were calculated for the crystallized films from the diffractograms and it was found that germanium thin films has average lattice parameter $(a=4.69 \AA)$ that agree well with other references $[4,13]$. Comparison of the spectra of the specimens crystallized in the previously mentioned annealing procedure with reference spectra of crystalline germanium from a data bank gave evidence that our specimens were polycrystalline with a cubic face centered crystal structure as detailed in Table 1. 


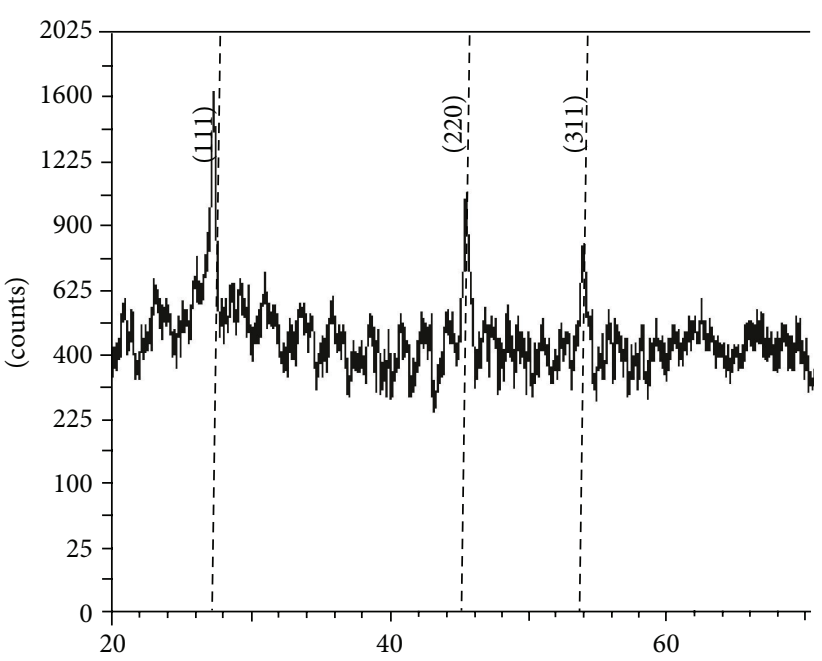

(a)

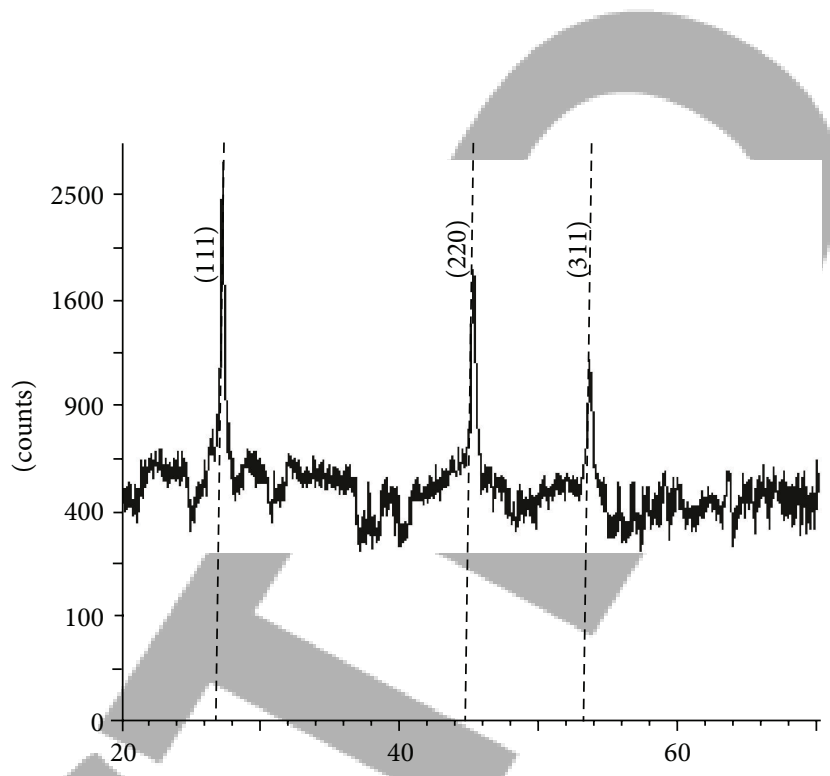

(b)

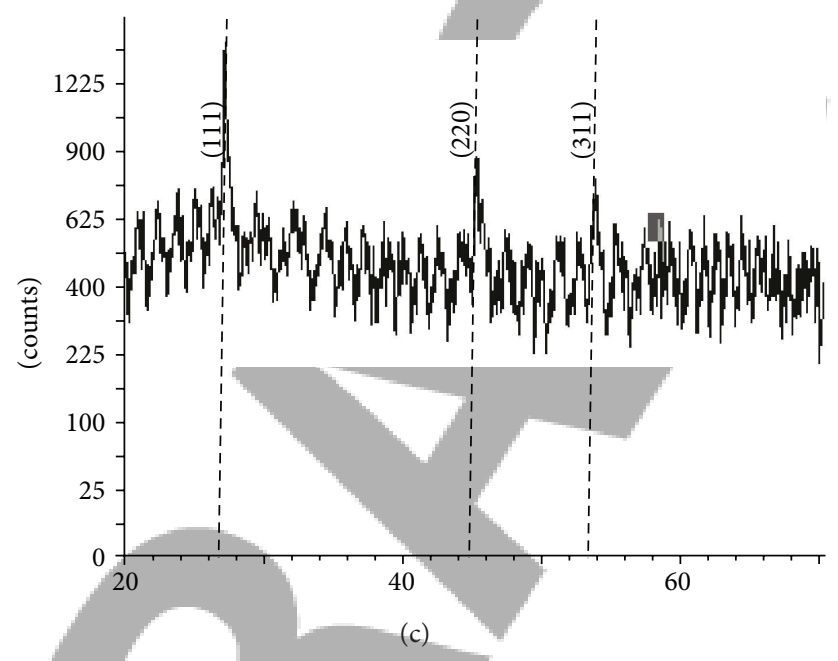

FIgURE 3: Example of the XRD spectra for films as a function for annealing temperatures (a) $500^{\circ} \mathrm{C}$, (b) $525^{\circ} \mathrm{C}$, and (c) $550^{\circ} \mathrm{C}$.

TABLE 1: Comparison of the specifications of the investigated Germanium films with the specifications of the previous Germanium films (data bank).

\begin{tabular}{|c|c|c|c|c|c|c|c|c|c|c|}
\hline \multicolumn{4}{|c|}{ The investigated samples } & \multirow{2}{*}{$h K L$} & \multirow{2}{*}{$t(\mathrm{~nm})$} & \multirow{2}{*}{$T\left({ }^{\circ} \mathrm{C}\right)$} & \multicolumn{4}{|c|}{ The referenced samples } \\
\hline$d(\AA)$ & $a(\AA)$ & $2 \theta^{\circ}$ & $I / I_{0}$ & & & & $d(\AA)$ & $a(\AA)$ & $2 \theta^{\circ}$ & $I / I_{0}$ \\
\hline 3.273 & 5.669 & 27.255 & 100 & 111 & & & 3.266 & 5.658 & 27.306 & 100 \\
\hline 1.995 & 5.642 & 45.485 & 39.1 & 220 & 790 & $500(30 \mathrm{~min})$ & 2.000 & 5.656 & 45.343 & 57 \\
\hline 1.702 & 5.645 & 53.885 & 28.5 & 311 & & & 1.706 & 5.658 & 53.728 & 39 \\
\hline 3.268 & 5.660 & 27.300 & 100 & 111 & & & 3.266 & 5.658 & 27.306 & 100 \\
\hline 1.999 & 5.654 & 45.385 & 43 & 220 & 790 & $525(30 \mathrm{~min})$ & 2.000 & 5.656 & 45.343 & 57 \\
\hline 1.703 & 5.648 & 53.860 & 22 & 311 & & & 1.706 & 5.658 & 53.728 & 39 \\
\hline 3.257 & 5.641 & 27.390 & 100 & 111 & & & 3.266 & 5.658 & 27.306 & 100 \\
\hline 1.989 & 5.625 & 45.625 & 35.6 & 220 & 790 & $550(30 \mathrm{~min})$ & 2.000 & 5.656 & 45.343 & 57 \\
\hline 1.703 & 5.648 & 53.850 & 32.2 & 311 & & & 1.706 & 5.658 & 53.728 & 39 \\
\hline
\end{tabular}

Figure 4 shows some examples for SEM images of films with an amorphous film Figure 4(a) and films with crystalline structure Figures 4(b) and 4(c).

The images showed that the verification change of the structural of the germanium was from the amorphous phase to the crystalline phase.
Figure 5 shows transmittance $(T)$ spectra Figure 5(a) and reflectance $(R)$ spectra Figure 5(b) of amorphous films and a polycrystalline film which annealed at $525^{\circ} \mathrm{C}$ for duration of $30 \mathrm{~min}$. From this figure we can noticed that the transmittance region for the crystallized film is larger than that for amorphous film, where the reflectance region of 

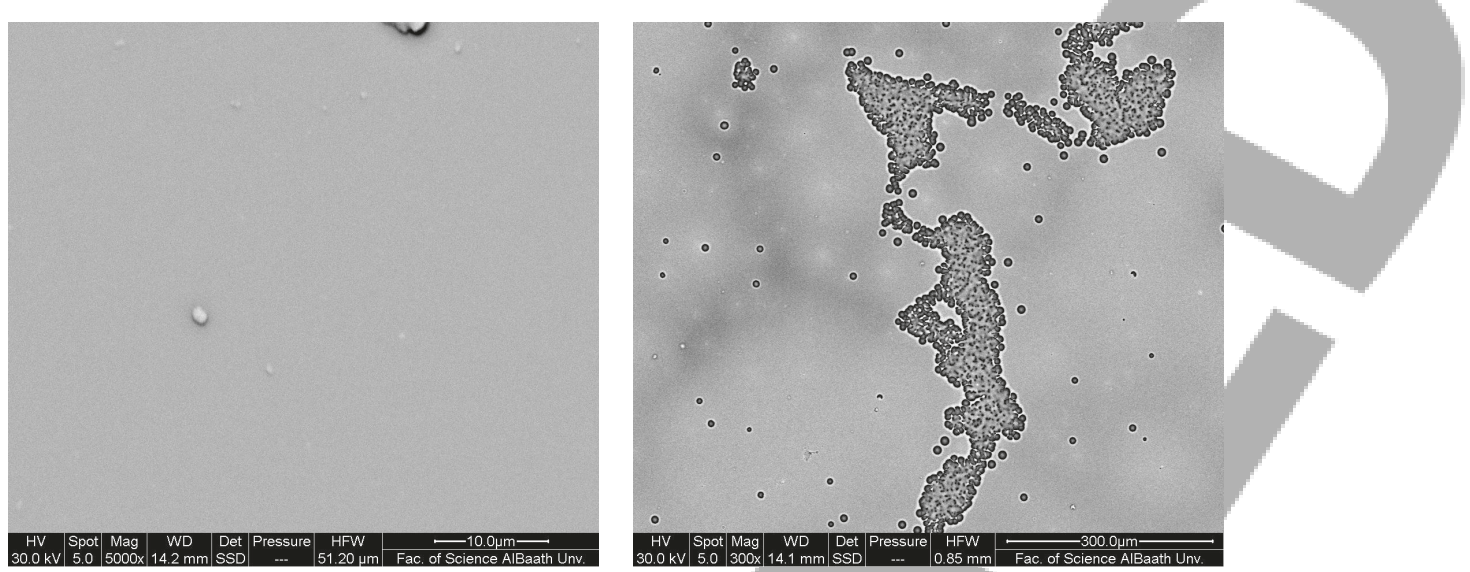

(a)

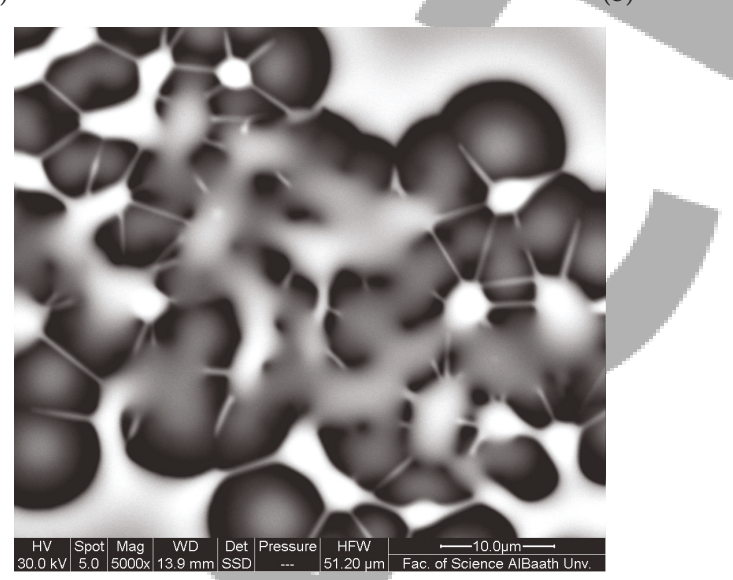

(c)

FIGURE 4: SEM images of (a) amorphous films, (b) cluster of germanium crystals, and (c) enlarged with the boundaries between each other appearing clearly.
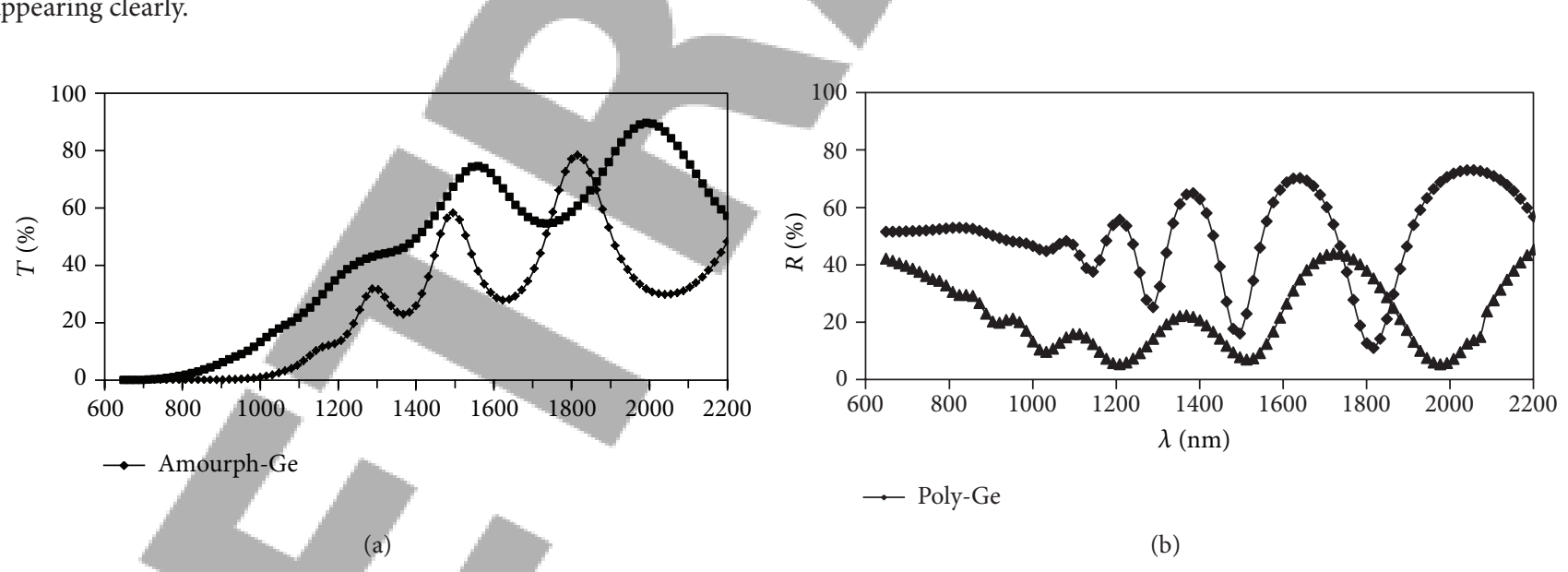

$\longrightarrow$ Poly-Ge

(b)

Figure 5: (a) Transmittance (T\%) and (b) reflectance spectra ( $R \%)$ for amorphous and crystalline films.

the amorphous film is larger than that for the crystallized film. The amorphous film shows a number of bottoms and peaks which may correspond to a larger number of electronic transitions as expected due to the more complicated band structure.

Figure 6 shows the transmittance $(T)$ spectrum Figure 6(a) and the reflectance Figure 6(b) spectrum for some crystallized films as a function for thickness. It can be seen that the transmittance for most spectral range decreases with increasing thickness, where a larger quantity of light is scattered in the material. The reflectance is larger for the thinner film, this agrees with the result of author [10]. There appears to be edges near the expected energy values of the band gaps, corresponding to the indirect $(\sim 0.6 \mathrm{eV})$ and the direct $(\sim 0.8 \mathrm{eV})$ electronic transitions. If light is incident on a germanium film the light is transmited 


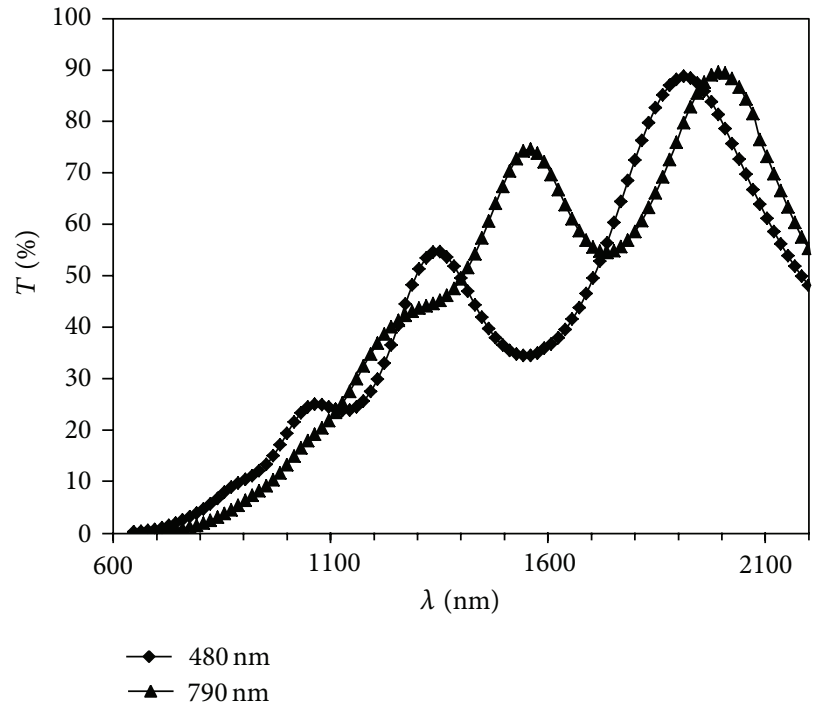

(a)

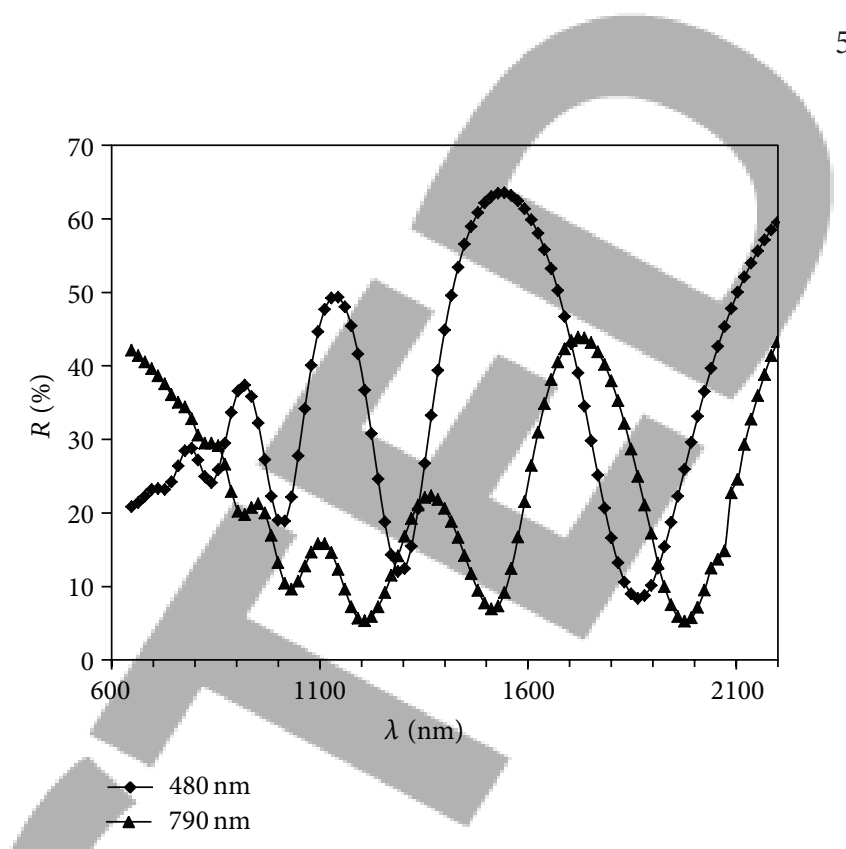

(b)

FIgURE 6: (a) Transmittance spectra and (b) reflectance spectra for crystallized films with varying thickness.

into the film and begins to interact with the electronic structure of the germanium. Hence, electronic transitions occur from the valence region to the conducting region, which cause absorption in the near infrared. In particular, there are two types of transitions: indirect $(\approx 0.6 \mathrm{eV})$ and direct $(\approx 0.8 \mathrm{eV})$ and we will verify their existence in the absorption spectrum of the obtained films. Absorption can be determined experimentally in semiconductors starting from Lambert's law, equation, which takes into account reflection effects [14]:

$$
I_{t}=(1-R) I_{o}
$$

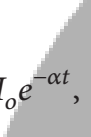

and

nd $I_{o}$ and $I_{t}$ the intensities of the irradiated and the transmitted light, respectively. $\alpha$ is the absorption coefficient which is given by the following equation:

$$
\alpha=\frac{2.303}{t} \log \left(\frac{1-R}{T}\right) .
$$

Given values for $t, R$, and $T$, we can determine the absorption coefficient of the amorphous and the crystallized films. Figure 7(a), shows the absorption coefficient for crystalline and amorphous germanium films, where indirect and direct absorption effects are visible. Figure 7(b) shows the variation of the absorption spectrum of crystallized germanium films as a function for thickness. For the description of the dependence of the absorption behavior of amorphous and likewise crystallized materials on the energy of the photon, theoretical models were invented, most important of which are the models of Taue and Davis-Mott $[14,15]$ :

$$
\alpha h v=B\left(h v-E_{g}\right)^{m}
$$

where $B$ is a material specific constant. To a certain degree, this can be understood as an experimental relation, which can be used to determine a good agreement with the direct or indirect transition energy $E_{\text {opt }}$. The power $m$ takes several values depending on the nature of the optical transition [15]. For direct allowed transitions, $m=1 / 2$, for the direct forbidden transitions, $m=3 / 2$, while $m=2$ and $m=3$ correspond to indirect allowed and forbidden transitions. The curves of the absorption coefficient (Figure 7) are showed that the different regions of absorption related to direct and indirect electron transitions.

For the calculation of the size of the corresponding energy gaps we divided the absorption spectrum of the germanium into regions corresponding to the two kinds of transitions mentioned above and calculated the band gap from the relation:

$$
\alpha h v=B\left(h v-E_{\mathrm{gi}}\right)^{2},
$$

for indirect transitions and from the relation:

$$
\alpha h v=B\left(h v-E_{\mathrm{gd}}\right)^{1 / 2}
$$

for direct transitions.

Using (4) we plotted $(\alpha h \nu)^{1 / 2}$ as a function of the photon energy $h v$ for the crystallized and amorphous films as shown in Figure 8(a) and determined $E_{\text {gi }}$ from the intersection of the curve with the $h v$ axis. In the same way, by plotting $(\alpha h \nu)^{2}$ as function of the photon energy $h v$ and using (5), we determined $E_{\text {gd }}$ for the crystallized and amorphous films as shown in Figure 8(b). In Table 2, the values of the band gaps for the indirect and the direct transitions are given for the amorphous and the crystallized specimens. These results are in agreement with various authors [4-7].

\section{Conclusions}

(1) Converting amorphous germanium films deposited on glass substrates into films with a polycrystalline 


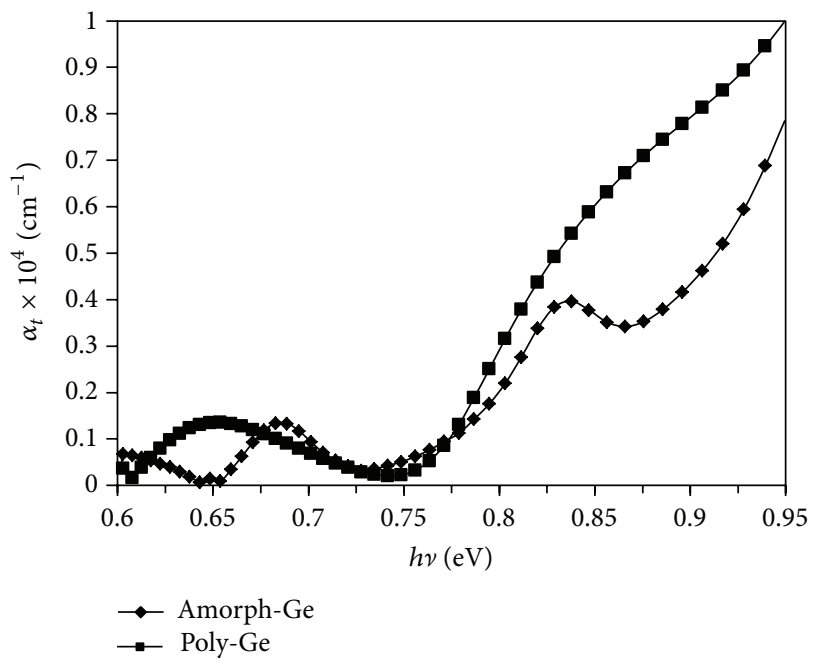

(a)

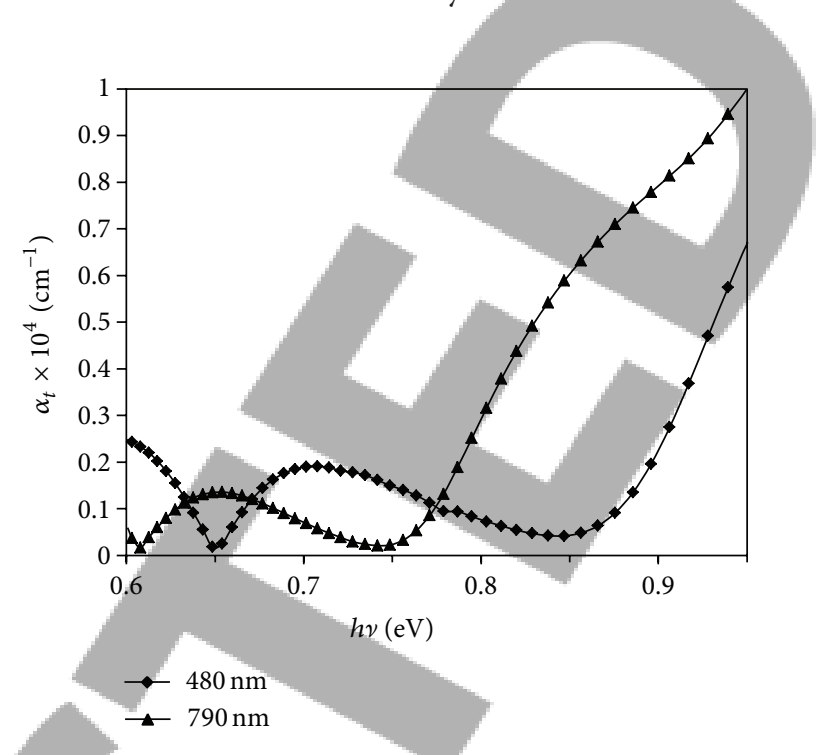

(b)

FIGURE 7: Absorption spectrum of (a) amorphous and crystallized germanium films and (b) variation of the absorption spectrum of crystallized germanium films with varying thickness.

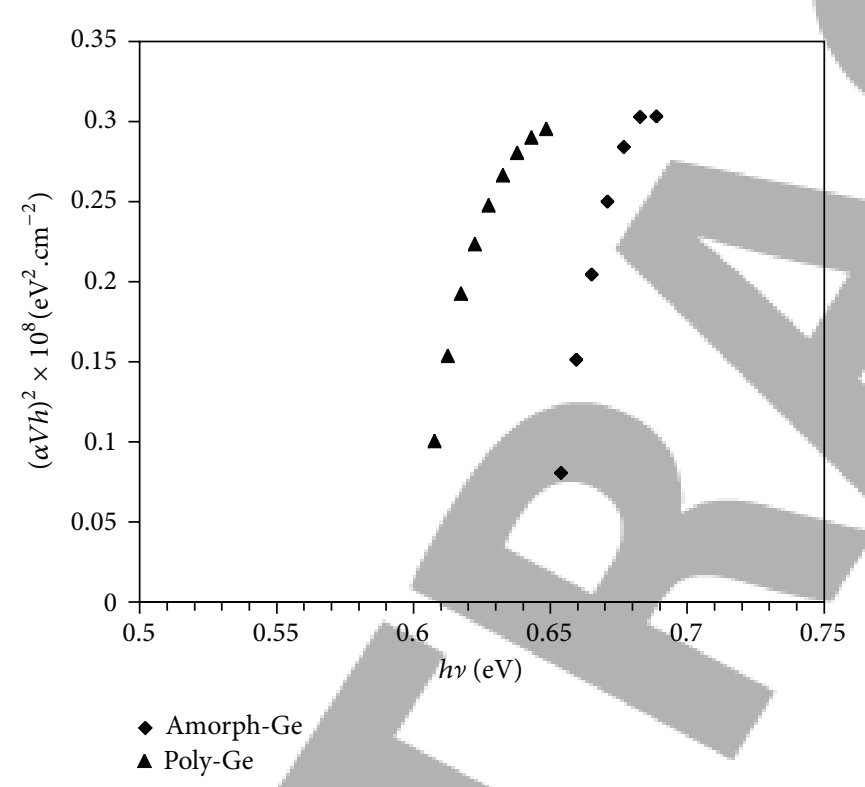

A Poly-Ge

(a)

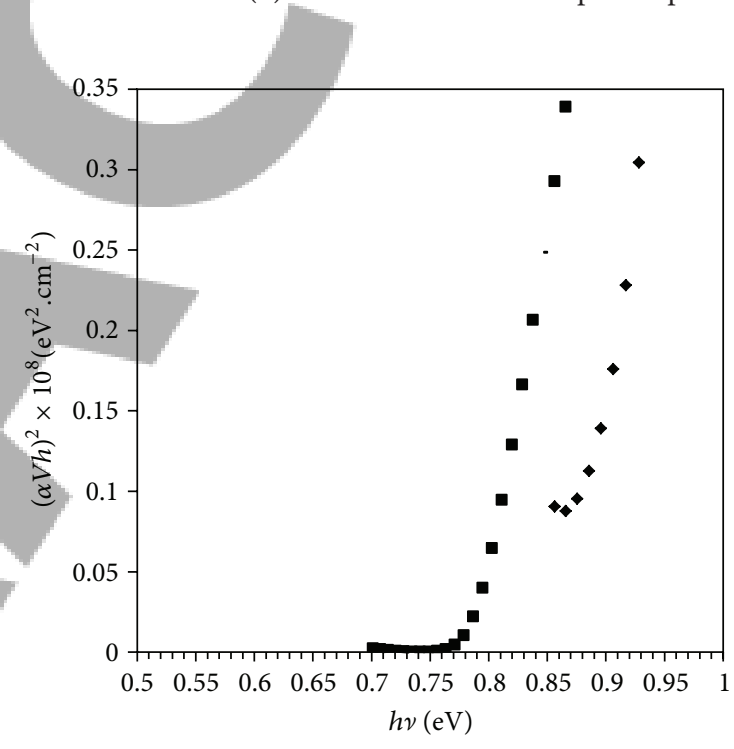

- Amorph-Ge

(b)

FIGURE 8: The energy gap $E_{\mathrm{gi}}$ (a) for indirect transitions and (b) $E_{\mathrm{gd}}$ for direct transitions for amorphous and polycrystalline films.

TABLE 2: Average values of direct and indirect band gaps for the amorphous and crystallized films.

\begin{tabular}{lcc}
\hline Sample & Indirect gap $\left(E_{\mathrm{gi}}\right) \mathrm{eV}$ & Direct gap $\left(E_{\mathrm{gd}}\right) \mathrm{eV}$ \\
\hline Crystallized film & 0.795 & 0.6 \\
Amorphous film & 0.87 & 0.645 \\
\hline
\end{tabular}

cubic structure of diamond type (FCC) with a latticespacing with an average value of $(a \approx 5.649 \AA$ ) $)$ under annealing of films in temperature higher than $450^{\circ} \mathrm{C}$.

(2) The most suitable annealing temperature for appearance of a crystal structure was $525^{\circ} \mathrm{C}$ for a value of the film thickness around $(500-1000 \mathrm{~nm})$.
(3) The absorption coefficient exhibits absorption edges corresponding to direct and indirect electron transitions, for both the amorphous and crystallized germanium films.

(4) The average value of $E_{g}$ for the indirect electronic transitions was $0.62 \mathrm{eV}$ while the direct electronic transitions is $0.85 \mathrm{eV}$.

\section{Conflict of Interests}

The authors declare that there is no conflict of interests regarding the publication of this paper. 


\section{References}

[1] M. Zacharias and P. M. Fauchet, "Light emission from Ge and $\mathrm{GeO}_{2}$ nanocrystals," Journal of Non-Crystalline Solids, vol. 227230, part 2, pp. 1058-1062, 1998.

[2] S. Sedky, P. Fiorini, M. Caymax, A. Verbist, and C. Baert, "IR bolometers made of polycrystalline silicon germanium," Sensors and Actuators A, vol. 66, no. 1-3, pp. 193-199, 1998.

[3] S. K. Agarwal, R. Tyagi, M. Singh, and R. K. Jain, "Effect of growth parameters on the MOVPE of GaAs/Ge for solar cell applications," Solar Energy Materials and Solar Cells, vol. 59, no. 1-2, pp. 19-26, 1999.

[4] P. Bhattaarya, Semiconductor Optoelectronic Devices, University of Michigan, Prentice-Hall, New York, NY, USA.

[5] G. Blaykor, Solid-State Physics, Izdatlstva Meer, Moscow, Russia, 1988.

[6] K. V. Shalomova, Physics of Semiconductors, Energoatomizdat, Moscow, Russia, 1985.

[7] V. L. Bonch-Broevich and C. G. Kalashnikov, Physics of Semiconductors, Nauka, Moscow, Russia, 1990.

[8] H. E. Bennett, J. M. Bennett, and J. P. Hirth, Physics of Thin Films, vol. 4, Academic press, New York, NY, USA, 1967.

[9] M. H. Farncombe and J. L. Vossen, Physics of Thin Films, Academic Press, San Diego, Calif, USA, 1992.

[10] V. F. Mitin, V. V. Kholevchuk, R. V. Konakova, E. F. Venger, and V. A. Odrich, "Surface structure and electrical properties of Ge films on semi-insulating GaAs substrates," in Proceedings of the 23th International conference on Microelectronics (MIEL '02), vol. 1, pp. 401-404, Nis, Serbia, 2002.

[11] R. K. Ahrenkiel, S. P. Ahrenkiel, M. M. Al-Jassim, and R. Venkatasubramanian, "Electronic and mechanical properties of $\mathrm{Ge}$ films grown on glass substrates," in Proceedings of the 26th IEEE Photovoltaic Specialists Conference, pp. 527-529, Anaheim, Calif, USA, October 1997.

[12] B. Bianand, T. Ohkubo, and Y. Hirotsu, "Crystallization and fractal formation in annealed a-Ge/Au bilayer films," Journal of Electron Microscopy, vol. 4, no. 4, pp. 182-190, 1995.

[13] H. S. Nalwa, Handbook of Thin Film Materials, vol. 5, Academic Press, New York, NY, USA, 2002.

[14] P. S. Kireev, Semiconductor Physics, Mir, Moscow, Russia, 1977.

[15] A. Ibrahim and S. K. J. Al-Ani, "Models of optical absorption in amorphous semiconductors at the absorption edge-a review and re-evaluation," Czechoslovak Journal of Physics, vol. 44, no. 8, pp. 785-797, 1994.
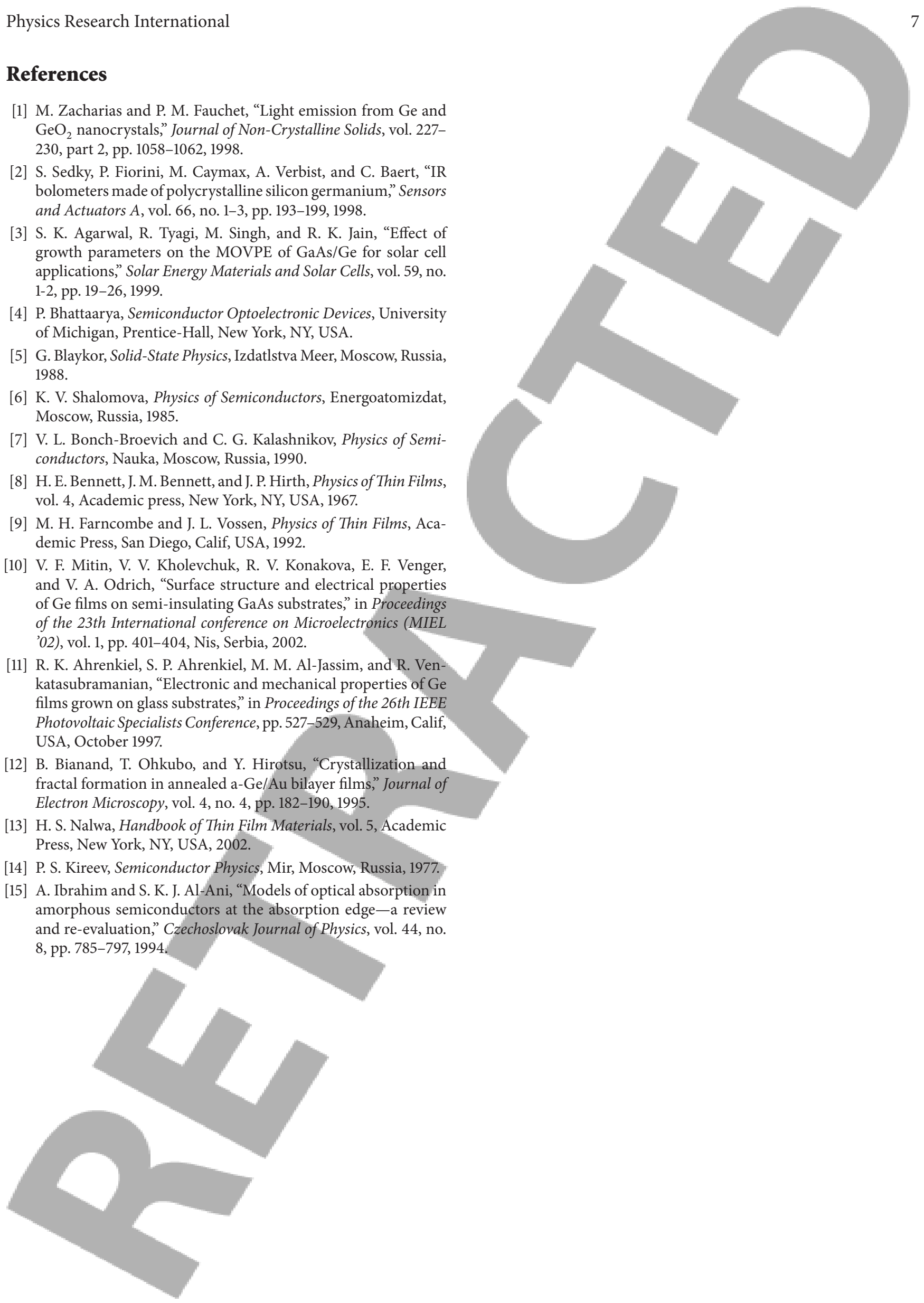